\title{
Visual Experience Induces Long-Term Potentiation in the Primary Visual Cortex
}

\author{
Sam F. Cooke and Mark F. Bear \\ The Picower Institute for Learning and Memory, Howard Hughes Medical Institute, Massachusetts Institute of Technology, Cambridge, \\ Massachusetts 02139
}

\begin{abstract}
Stimulus-specific response potentiation (SRP) is a robust form of experience-dependent plasticity that occurs in primary visual cortex. In awake mice, visual evoked potentials (VEPs) recorded in layer 4 of binocular visual cortex undergo increases in amplitude with repeated presentation of a sinusoidal grating stimulus over days. This effect is highly specific to the experienced stimulus. Here, we test whether the mechanisms of thalamocortical long-term potentiation (LTP), induced with a theta burst electrical stimulation (TBS) of the dorsal lateral geniculate nucleus, are sufficient to account for SRP. First, we demonstrate that LTP similarly enhances the amplitude of VEPs, but in a way that generalizes across multiple stimuli, spatial frequencies, and contrasts. Second, we show that LTP occludes the subsequent expression of SRP. Third, we reveal that previous SRP occludes TBS-induced LTP of the VEP evoked by the experienced stimulus, but not by unfamiliar stimuli. Finally, we show that SRP is rapidly and selectively reversed by local cortical infusion of a peptide that inhibits $\mathrm{PKM} \zeta$, a constitutively active kinase known to maintain NMDA receptor-dependent LTP and memory. Thus, SRP is expressed by the same core mechanisms as LTP. SRP therefore provides a simple assay to assess the integrity of LTP in the intact nervous system. Moreover, the results suggest that LTP of visual cortex, like SRP, can potentially be exploited to improve vision.
\end{abstract}

\section{Introduction}

Long-term potentiation (LTP) is a form of synaptic plasticity elicited in the brain by patterned electrical stimulation (Bliss and Lømo, 1973). The mechanisms of LTP have been elucidated in numerous studies motivated by the belief that this phenomenon reveals a core process of experience-dependent information storage that may go awry in psychiatric disorders and be targeted by therapies designed to correct them (Martin et al., 2000; Malenka and Bear, 2004; Neves et al., 2008). Although LTP-like changes have been shown to occur after several types of behavioral training (Doyère et al., 1995; Rioult-Pedotti et al., 2000; Schafe et al., 2005; Gruart et al., 2006; Whitlock et al., 2006; Tye et al., 2008), it has yet to be determined that these synaptic modifications are sufficient to account for the resulting memory (Neves et al., 2008). This is a difficult determination to make, particularly in the case of memories that are encoded by sparse, iterative, and widely distributed synaptic modifications deep inside the brain (i.e., many synapses away from the sensory periphery). Consequently, there is no established, noninvasive paradigm in which one can be confident that a measured change in electrophysiological response or behavior is attributable specifically to induction of LTP.

Received Aug. 16, 2010; revised Sept. 29, 2010; accepted Oct. 2, 2010.

This work was supported by the Howard Hughes Medical Institute and the National Institutes of Health (NIH) (M.F.B.), NIH-National Eye Institute Grant R01 EY018323-01. We thank Arnold Heynen for helpful advice and discussions, and Erik Sklar, Kathleen Oram, and Suzanne Meagher for assistance.

Correspondence should be addressed to Mark F. Bear, The Picower Institute for Learning and Memory, Massachusetts Institute of Technology, 46-3301, 43 Vassar Street, Cambridge, MA 02139. E-mail: mbear@mit.edu.

DOI:10.1523/JNEUROSCI.4333-10.2010

Copyright $\odot 2010$ the authors $\quad$ 0270-6474/10/3016304-10\$15.00/0
In the current study, we examine the possibility that the mechanism of LTP may be sufficient to account for a surrogate electrophysiological measure of perceptual learning in the mouse visual system. In multiple sensory modalities and species, it has been shown that repeated presentation of a sensory stimulus results in sensory gains that may be highly specific to the familiar stimulus (Poggio et al., 1992; Fahle and Morgan, 1996). The lack of transfer in perceptual learning from one stimulus to another has led to the suggestion that the underlying plasticity occurs in primary sensory cortex (Karni and Bertini, 1997; Gilbert et al., 2001). Imaging studies in humans support this hypothesis (Furmanski et al., 2004) and recording directly from mouse primary visual cortex reveals that local plasticity does occur after repeated exposure to visual stimuli (Frenkel et al., 2006). Stimulus-specific response potentiation (SRP) of the cortical visual evoked potential (VEP) occurs in response to brief daily presentation of a particular visual stimulus. SRP is input-specific and long-lasting, and is prevented by blockade of NMDA receptors and by cortical delivery of a peptide that inhibits AMPA receptor insertion. All these properties resemble those of canonical LTP.

Here, we use the VEP as an assay to determine whether electrically induced geniculocortical LTP has equivalent functional effects to SRP. Our experiments reveal that LTP and SRP mimic and mutually occlude one another. Additionally, we find that established SRP is rapidly erased by injection of a peptide that has been shown to reverse LTP in the hippocampus. The mechanisms of LTP therefore are necessary and sufficient to account for SRP. These findings strengthen the hypothesis that LTP is a mechanism for perceptual learning and suggest that SRP is a simple assay to assess the integrity of LTP in the intact nervous system. 


\section{Materials and Methods}

Animals. All animals were male C57BL/6 mice (Charles River Laboratories). Animals were implanted on postnatal day 30 (P30). Mice were group housed with food and water available ad libitum and maintained

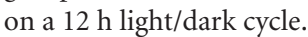

Electrode implantation. Mice were anesthetized with an intraperitoneal injection of $50 \mathrm{mg} / \mathrm{kg}$ ketamine and $10 \mathrm{mg} / \mathrm{kg}$ xylazine. The $1 \%$ lidocaine hydrochloride anesthetic was injected locally under the scalp of the mouse before incision. The skull was then cleaned with iodine and $70 \%$ ethanol. A steel headpost was then affixed to the skull just anterior to bregma using cyanoacrylate glue for subsequent head restraint. Small $(<0.5 \mathrm{~mm})$ burr holes were drilled in the skull overlying the binocular visual cortex (3.2 mm lateral of lambda). Tapered tungsten microelectrodes (FHC), $75 \mu \mathrm{m}$ in diameter at their widest point, were inserted in each hemisphere and positioned $470 \mu \mathrm{m}$ below the cortical surface in the stereotaxic dorsal-ventral axis. Silver wire (A-M Systems) reference electrodes were placed bilaterally over prefrontal cortex. All electrodes were then secured in place using cyanoacrylate glue. Circular plastic walls (cut from pipette tips) were glued into place to create a $3 \times 3 \mathrm{~mm}$ exposed aperture above the skull for subsequent placement of a stimulating electrode into the lateral geniculate nucleus (LGN) (see Fig. 1A). A permanent marker was used to demarcate the site of entry for LGN stimulation (2.1 $\mathrm{mm}$ posterior to bregma, $2.2 \mathrm{~mm}$ lateral to midline). Dental cement was applied to cover the remaining skull and enclose all electrodes into a stable, protective head cap. Animals were monitored postoperatively for signs of infection or discomfort and were allowed at least $24 \mathrm{~h}$ recovery before habituation to the restraint apparatus.

VEP recording. VEP recordings were conducted in awake, headrestrained mice. Animals were habituated to the restraint apparatus before recording by sitting in situ in front of a gray screen. The animals remained still but alert during subsequent presentation of discrete visual stimuli. VEP amplitude was quantified by measuring trough-peak response amplitude, as described previously (Sawtell et al., 2003; Frenkel and Bear, 2004). For most experiments, animals were presented with 400 phase reversals of each oriented stimulus, delivered binocularly, on a given day. For acuity/contrast sensitivity experiments, in which a large number of different stimuli were presented in each session, the number of phase reversals averaged for each stimulus was reduced to 200 .

ZIP infusions. Animals underwent the normal VEP electrode implantation surgery under ketamine/xylazine anesthesia but were also implanted bilaterally with 26 gauge guide cannulae (Plastics One). Guide cannulae were positioned just lateral to the recording electrode at a $45^{\circ}$ angle to the skull so as to target the VEP recording site, and lowered 0.1 $\mathrm{mm}$ below surface. Guide cannulae were then fixed in place with cyanoacrylate glue and dental cement. Dummy cannulae were inserted. Animals were allowed to recover and habituated to the recording apparatus for $2 \mathrm{~d}$ before experiments. On the first day of VEP recording, dummy cannulae were removed to determine whether physical displacement would, in any way, affect the VEP. They were repositioned at the end of the recording session. Solutions were prepared on the day of injection. Syringes and guide tubing attached to 33 gauge injection cannulae were filled with distilled water, which was separated from the injected solution with an air bubble. Dummies were again removed, and injection cannulae were inserted through guides and allowed to sit in place for $5 \mathrm{~min}$ before injection. Slight positive pressure was maintained on the syringe while inserting the injection cannulae, using a KD Scientific infusion pump, to prevent blockage. Myr-SIYRRGARRWRKL-OH (ZIP) (Invitrogen), the specific pseudosubstrate inhibitor of $\mathrm{PKM} \zeta$, was dissolved in artificial CSF to a concentration of $10 \mathrm{nmol} / \mu \mathrm{l}$. One microliter was infused over the course of 10 min using the infusion pump. Scrambled control (myr-RLYRKRIWRSAGR-OH) was prepared to the equivalent concentration and infused in the same manner.

Visual stimuli. Visual stimuli consisted of full-field, 100\% contrast, sinusoidal gratings generated by a VSG2/2 card (Cambridge Research System) and presented, linearized by $\gamma$ correction, on a computer monitor. VEPs were elicited by vertical $\left(90^{\circ}\right)$, or oblique $\left(45\right.$ or $\left.135^{\circ}\right)$ bars, phase reversing at a frequency of $0.5 \mathrm{~Hz}$. For acuity experiments, stimuli ranged across $0.05,0.15,0.3,0.45,0.6,0.8$, and $1 \mathrm{cycle}^{\circ}$, and for contrast sensitivity experiments stimuli ranged across $0,1.5,3.125,6.25,12.5,25$, 50 , and $100 \%$ contrast. The display was positioned $20 \mathrm{~cm}$ in front of the mouse and centered on the midline, thereby occupying $92 \times 66^{\circ}$ of the visual field. Mean luminance, determined by a photodiode placed in front of the computer screen, was $27 \mathrm{~cd} / \mathrm{m}^{2}$.

Thalamic stimulation. Animals were kept in the dark for $2 \mathrm{~h}$ before in vivo LTP experiments. Mice were transiently anesthetized under isoflurane $(1 \%)$ while positioned in the VEP recording apparatus (body temperature was maintained using a small heating blanket). A burr hole was drilled according to previous demarcation $(2.1 \mathrm{~mm}$ anteroposterior, 2.2 $\mathrm{mm}$ mediolateral), and a stainless-steel concentric bipolar stimulating electrode (FHC), $200 \mu \mathrm{m}$ in diameter with a $25 \mu \mathrm{m}$ Pt/Ir inner pole, was advanced slowly from surface. Stimuli $(0.2 \mathrm{~ms}$ pulse width) were applied every $10 \mathrm{~s}$ while recording evoked field potentials through chronically implanted recording electrodes. Approximately $2.4-2.5 \mathrm{~mm}$ from surface, a monosynaptically driven field potential was detected, indicating arrival at the dorsal lateral geniculate nucleus (dLGN), and depth was finely adjusted to optimize the response amplitude. Given the proximity of the dLGN to the overlying hippocampus, it was essential that we distinguish between volume-conducted electrical responses in visual cortex elicited by hippocampal stimulation and synaptic field potentials resulting from thalamic stimulation. In initial experiments, we recorded light flash-evoked multiunit activity through the stimulating electrode to determine when we were positioned in the dLGN. Such evoked activity does not occur in hippocampus. This enabled us to determine that a signature of hippocampal-mediated, volume-conducted responses is their relatively long latency and characteristic positive-going morphology that does not change regardless of recording electrode depth. The optimal short-latency field potential was observed when the electrode was in contact with the optic radiation fibers emitted from the anterior pole of the dLGN. Field potentials were evoked at $60 \%$ maximum using a stimulus intensity ranging from 0.1 to $0.7 \mathrm{~mA}$. Once stable, field potentials were evoked every $30 \mathrm{~s}$ over a half-hour baseline before inducing LTP with theta burst stimulation (TBS). TBS consisted of bursts of six pulses delivered at $100 \mathrm{~Hz}$, repeated six times at a frequency of $10 \mathrm{~Hz}$, all of which was repeated six times, separated by $20 \mathrm{~s}$ intervals. This whole tetanus was repeated three times with an interval of $5 \mathrm{~min}$ between each to saturate LTP. Field potentials were then followed for $1 \mathrm{~h}$ before removal of the stimulating electrode, application of dental cement to cover the craniotomy, and recovery of the animal from isoflurane anesthesia in the home cage. LTP data were normalized, averaged, and reported as mean \pm SEM. Changes in synaptic strength were measured by comparing the average response amplitude 50-60 min after the final TBS stimulation to the pretetanus baseline response.

Histology. Formalin perfusion and histology were performed after all experiments. Chronically implanted recording electrode position was determined by making an electrolytic lesions and staining fixed, sectioned brains with cresyl violet. The position of acutely placed stimulating electrodes in the dLGN was also confirmed in this manner.

Statistical analyses. LTP data are presented as a percentage of average pre-TBS baseline. Each presented sample point is an average of four recorded data points over $2 \mathrm{~min}$. VEP data are presented either raw or normalized (as described in the text and figure legends) and each data point is an average of 400 or 200 individual VEPs. All data are reported as mean \pm SEM. Comparison of electrically evoked potentials in LTP experiments were evaluated using a paired $t$ test. Single-day comparisons of either raw or normalized VEP amplitudes were made with unpaired $t$ tests for comparisons between two groups and paired $t$ tests for comparisons within animals. One-way ANOVA was applied for comparisons between three or more groups of VEPs and repeated-measures ANOVAs for comparisons across days. Fisher's least significant difference test was applied post hoc to determine which comparisons yielded significant difference.

\section{Results}

\section{Orientation selectivity of SRP}

As previously reported (Frenkel et al., 2006), repeated presentation of a phase-reversing, sinusoidal grating stimulus to a headfixed, awake mouse (Fig. $1 \mathrm{~A}$ ) results in a pronounced increase in 
A
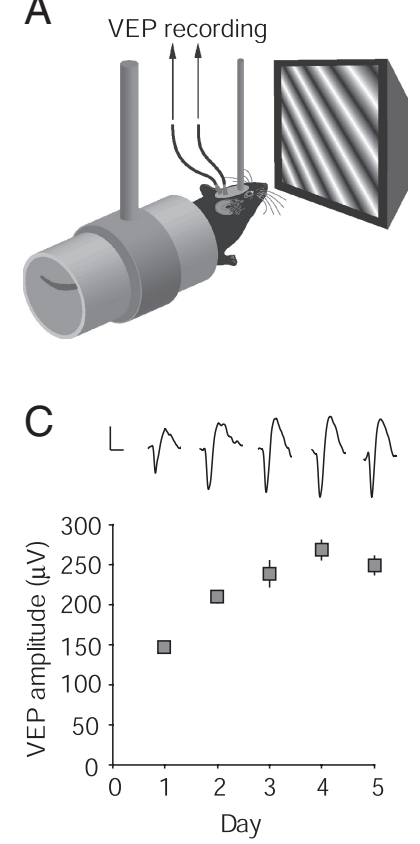

\section{E}

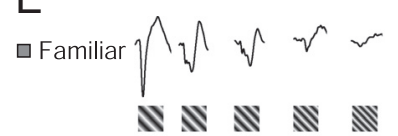

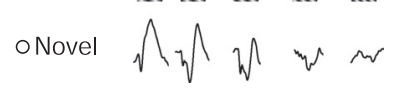
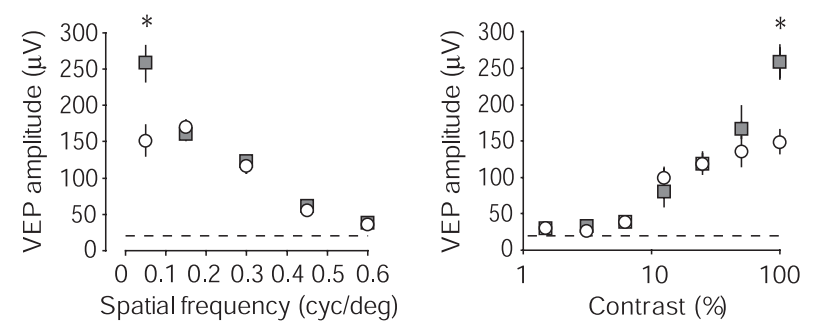

Figure 1. SRP. A, Schematic of experimental apparatus. VEPs were recorded from layer 4 of binocular primary visual cortex (V1). $\boldsymbol{B}$, Time course of experiments described within Figure 1. Mice were implanted with recording electrodes and head post was affixed at $P 30$. On recovery, mice were habituated to the apparatus on 2 consecutive days. Over the next $5 \mathrm{~d}$, VEPs were sampled, each driven by a $0.5 \mathrm{~Hz}$ phase-reversing, full-field, 0.05 cycle $/{ }^{\circ}, 100 \%$ contrast, sinusoidal grating stimulus, of $X^{\circ}$ orientation, and averaged each day (gray squares). On the final day, VEPs were evoked by a multitude of other stimuli, varying in spatial frequency, contrast, and orientation ( $\boldsymbol{D}$, white circles). $\boldsymbol{C}$, The averaged trough-peak VEP amplitude driven by $X^{\circ}$ increased significantly over days, reaching asymptote on day $5(n=7)$. D, VEPs driven by novel stimuli equivalent in all regards except being as little as $5^{\circ}$ different in orientation from familiar $X^{\circ}$ (white circles), were significantly lower amplitude than those driven by $X^{\circ}$. VEP amplitude is here presented as a percentage of those driven by an orthogonal orientation $\left(X+90^{\circ}\right.$, dotted horizontal line at $100 \%$ ). VEPs driven by orientations similar to $X^{\circ}$ were greater amplitude than $X+90^{\circ}$-driven VEPs out to a boundary of around $X \pm 25^{\circ}(n=7)$. E, Averaged VEPs driven by stimuli varying in spatial frequency, from 0.15 to 0.6 cycle $/{ }^{\circ}$, were equivalent in amplitude for either the familiar $X^{\circ}$ (gray squares) or unfamiliar $X+90^{\circ}$ stimulus (white circles) on day 5 . Only at the familiar spatial frequency of 0.05 cycle $/{ }^{\circ}$ did $X^{\circ}$ evoke a significantly larger VEP than $X+$

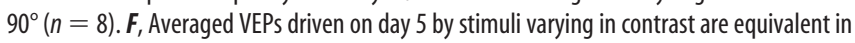
amplitude for either familiar $X^{\circ}$ (gray squares) or unfamiliar $X+90^{\circ}$ (white circles) for all contrast values other than the familiar $100 \%$ contrast, at which $X^{\circ}$ evoked significantly greater amplitude VEPs than $X+90^{\circ}$. Error bars in all graphs are SEM. Example VEPs are presented for each day above the relevant graph point for $\mathbf{C}-\boldsymbol{F}$. Calibration: vertical, $100 \mu \mathrm{V}$; horizontal, 50 ms. VEP traces represent an average of $200 \mathrm{EEG}$ samples after visual stimulus phase reversal. Traces run from phase reversal onset, such that the average response onset is $\sim 25 \mathrm{~ms}$ and the average peak negativity is $\sim 50 \mathrm{~ms}$ after visual stimulus phase reversal. Asterisks represent statistical comparisons yielding a significant difference $(p<0.05)$. the trough-peak amplitude of averaged VEPs recorded from layer 4 of binocular visual cortex. This phenomenon is described as stimulus-specific because the enhanced VEP is not driven by stimuli of different orientations. Here, we further investigated the specificity of SRP by varying the orientation, spatial frequency, or contrast of test stimuli after SRP had been saturated to a $0.5 \mathrm{~Hz}$ phase-reversing, full-field, $0.05 \mathrm{cycle}^{\circ}, 100 \%$ contrast stimulus of a particular oblique orientation (henceforth termed $X^{\circ}$, because the orientation was varied from animal to animal) presented binocularly (for experimental time line, see Fig. $1 B$ ). SRP developed gradually over the course of $5 \mathrm{~d}$. The amplitude of VEPs recorded on day $1(144.8 \pm 14.6 \mu \mathrm{V})$ approximately doubled by day $5(269.1 \pm 20.9 \mu \mathrm{V}, n=7$; one-way repeatedmeasures ANOVA, $F_{(4,6)}=22.4, p<0.0001$ ) (Fig. 1C). On day 5 , once SRP had been saturated, several different novel orientations of stimuli were presented, randomly interleaved, to determine the degree of orientation specificity of SRP. The amplitude of VEPs driven by these novel orientations are presented in Figure $1 D$. A stimulus just $5^{\circ}$ different in orientation from the familiar $X^{\circ}$ stimulus evoked VEPs of significantly lower amplitude (136.4 $\pm 12.6 \%$ day 1 VEP amplitude) than the familiar stimulus $\left(F_{(6,42)}=2.799, p<0.05\right.$; Fisher's post hoc test for comparison of familiar $X^{\circ}$ orientation with $X+5^{\circ}$ orientation, $p<0.05)$. Thus, for orientation at least, SRP can be described as exquisitely specific.

SRP at a single spatial frequency or contrast does not result in a shift in acuity or contrast sensitivity

We continued to investigate the specificity of SRP by presenting familiar $X^{\circ}$ and novel $X+90^{\circ}$-oriented stimuli at varying spatial frequency or contrast. These results are presented in Figure 1, $E$ and $F$, respectively. At a fixed contrast of $100 \%$, stimuli of 0.05 , $0.15,0.3,0.45$, and 0.6 cycle $/{ }^{\circ}$ evoked VEPs discernible over noise (as determined with a static gray screen). At the lowest spatial frequency of $0.6 \mathrm{cycle} /{ }^{\circ}$, VEPs were significantly greater amplitude $(43.6 \pm 5.1 \mu \mathrm{V})$ than trough-peak measurements for a gray screen $\left(27.8 \pm 2.4 \mu \mathrm{V}\right.$; paired $t$ test, $\left.t_{(6)}=5.02 ; p<0.005\right)$. All unfamiliar spatial frequencies evoked VEPs of equivalent magnitudes at the two orientations (two-way repeated-measures ANOVA, $F_{(1,3)}=0.328, p=0.805$ for the interaction effects of stimulus orientation and spatial frequency). The familiar spatial frequency of $0.05 \mathrm{cycle}^{\circ}$, at which the familiar $100 \%$ contrast $X^{\circ}$ orientation evoked VEPs $(256.2 \pm 20.7 \mu \mathrm{V})$ almost double the amplitude of those driven by the novel $X+90^{\circ}$ stimulus (147.6 \pm $17.5 \mu \mathrm{V}$ ) was significantly enhanced, because of SRP (paired $t$ test, $\left.t_{(6)}=7.81, p<0.0005\right)$. The same was true for contrast. Stimuli presented at contrast as low as $6.25 \%$ evoked VEPs $(37.5 \pm 2.7 \mu \mathrm{V})$ significantly discernible above trough-peak measurements for a gray screen $(27.8 \pm 2.4 \mu \mathrm{V}$; paired $t$ test, $t_{(6)}=2.52 ; p<0.05$; denoted by the dotted line in Fig. $\left.1 E, F\right)$. However, VEPs were of equivalent magnitude when driven by both familiar and novel stimuli at all contrast values other than the familiar $100 \%$ contrast (two-way repeated-measures ANOVA, $F_{(1,3)}=1.647, p=0.147$ for the interaction effects of stimulus orientation and contrast. Note that the familiar stimulus was both $100 \%$ contrast and $0.05 \mathrm{cycle}^{\circ}$, so VEP amplitudes and statistic are the same as those already given for the familiar $X^{\circ}$ orientation). Thus, repeated presentation of a stimulus at one spatial frequency or contrast did not result in a general enhancement of spatial acuity or contrast sensitivity. 

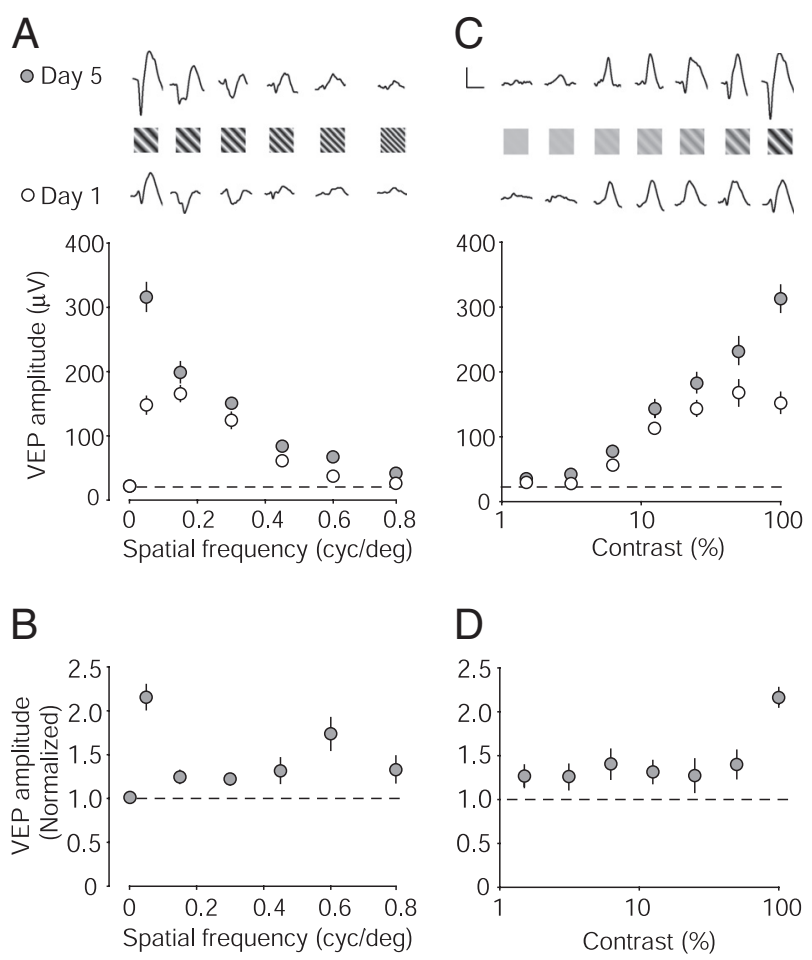

Figure 2. SRP across multiple spatial frequencies and contrasts enhances acuity and contrast sensitivity. $\boldsymbol{A}$, Awake, head-fixed mice were exposed to full-field, phase-reversing sinusoidal grating stimuli across a range of spatial frequencies $\left(0.05,0.15,0.3,0.45,0.6\right.$, and $\left.0.8 \mathrm{cycle} /{ }^{\circ}\right)$ at a set oblique orientation over $5 \mathrm{~d}$. VEP amplitude on day 5 (gray circles) and day 1 (white circles) was compared at each spatial frequency to determine spatial acuity for the two orientations $(n=9)$. Example VEPs are presented for both orientations in the top of the panel above graph points. Calibration: $100 \mu \mathrm{V}, 50 \mathrm{~ms}$. B, Experience-dependent gains in acuity are revealed by normalizing VEPs on day 5 (gray circles) to day 1. C, Mice were repeatedly exposed to a single oblique orientation across a range of contrast values $(0,1.5,3.125,6.25,12.5,25,50$, and $100 \%$ contrast) for $5 \mathrm{~d}$. VEP amplitude was increased across a range of contrasts on day 5 (gray circles) compared with day 1 (white circles). Example waveforms are presented at the top of the panel. $D$, Experience-dependent gains in contrast sensitivity are revealed by normalizing VEPs on day 5 (gray circles) to day 1. The dotted lines represent noise levels as determined with a static gray screen in both $\boldsymbol{C}$ and $\boldsymbol{D}$. Error bars are SEM.

\section{Repeated presentation of multiple stimuli enhances spatial acuity and contrast sensitivity}

To determine whether SRP, despite its specificity, could be used to enhance spatial acuity or contrast sensitivity, we then repeatedly presented a group of mice $(n=9)$ with a single $X^{\circ}$-oriented stimulus at a range of spatial frequencies and contrasts. After $5 \mathrm{~d}$ of repeated presentation of $100 \%$ contrast stimuli at $0.05,0.15$, $0.3,0.45,0.6,0.8 \mathrm{cycle}^{\circ}$, VEPs showed a varying degree of potentiation relative to day 1 (Fig. $2 A, B$ ). Notably, VEPs that were not discernible above noise levels $(22.2 \pm 1.6 \mu \mathrm{V}$; dotted lines $)$ at 0.8 cycle ${ }^{\circ}$ on day $1\left(30.6 \pm 2.0 \mu \mathrm{V}, n=9\right.$; paired $t$ test, $t_{(8)}=1.21$; $p=0.26)$ were small, but present on day $5(39.4 \pm 5.4 \mu \mathrm{V}$; paired $t$ test, $\left.t_{(8)}=3.31 ; p<0.05\right)$. The emergence of visual cortical activity driven by stimuli that did not evoke VEPs before visual experience suggests that spatial acuity can be modestly enhanced by SRP. Normalization of VEP amplitude on day 5 to day 1 (Fig. 2B) reveals that SRP increased visual cortical activity across all spatial frequencies (two-way repeated-measures ANOVA, $F_{(1,5)}=23.62$, $p<0.0001$ for the interaction effects of orientation and spatial frequency). Similarly, after repeated presentation of $0.05 \mathrm{cycle} /{ }^{\circ}$ stimuli across contrast values ranging from 0 to $100 \%$, VEPs emerged at $3.125 \%$ contrast $(41.6 \pm 7.1 \mu \mathrm{V})$ compared with noise levels measured to a gray screen $(27.8 \pm 2.4 \mu \mathrm{V}$; paired $t$ test, $t_{(8)}=3.73 ; p<0.01$ ) (Fig. $2 C, D$ ). On day 1 , this contrast did not drive VEPs $(26.2 \pm 1.6 \mu \mathrm{V})$ above noise levels, again suggesting that SRP could be used to enhance contrast sensitivity. Normalization of the amplitude of VEPs on day 5 to those on day 1 (Fig. 2D) reveals that SRP resulted in significant gains in visual cortical activity at $100,50,25,12.5,6.25$, and $3.125 \%$ contrast (two-way repeated-measures ANOVA, $F_{(1,6)}=11.903, p<$ 0.0001 for the interaction effects of orientation and contrast). Thus, SRP across multiple stimuli may serve as a means of enhancing visual acuity and contrast sensitivity.

\section{Application of TBS to dLGN induces thalamocortical LTP in the intact mouse}

It has previously been shown that thalamocortical LTP can be induced in vivo at dLGN-visual cortical synapses in the rat (Heynen and Bear, 2001). Here, we show that LTP can be induced in the mouse in a similar fashion (Fig. 3A). Responses recorded in layer 4 of binocular primary visual cortex (V1) underwent LTP after delivery of TBS $(n=20)$. Stability of the response was determined over a $30 \mathrm{~min}$ baseline period before induction of saturated LTP with three spaced bouts of TBS ( 5 min intertetanus interval). Responses were then evoked at the baseline interval of one every $30 \mathrm{~s}$ over a period of $1 \mathrm{~h}$ to assess the degree of LTP. Over the period of 50-60 min after the final TBS, field potential amplitude was $121 \pm 6.6 \%$ of baseline, indicating significant LTP (paired $t$ test for average value across last $10 \mathrm{~min}$ of baseline and $50-60$ min after final tetanus; $t_{(19)}=3.99 ; p<0.001$ ).

\section{Thalamocortical LTP mimics SRP in potentiating VEP amplitude}

We then tested whether thalamocortical LTP would impact the VEP itself. A subgroup of mice $(n=13)$ that underwent LTP as described above were allowed to recover overnight. VEPs were sampled the following day, evoked by $100 \%$ contrast, 0.05 cycle ${ }^{\circ}$ stimuli. In the hemisphere that had undergone LTP, VEPs were significantly greater amplitude $1 \mathrm{~d}$ after TBS $(187.7 \pm 23.8 \mu \mathrm{V})$ than in the control hemisphere that had not received TBS $\left(100.6 \pm 11.5 \mu \mathrm{V}, n=13\right.$; paired $t$ test, $\left.t_{(12)}=4.17, p<0.005\right)$, indicating that LTP had increased synaptic drive within layer 4 of visual cortex (Fig. 3C). We also determined whether or not TBS would exert a sustained effect over VEP amplitude by presenting a novel orthogonal stimulus $5 \mathrm{~d}$ after LTP in the same mice. Once again, averaged VEP amplitude in the previously tetanized hemisphere $(165.6 \pm 12.9 \mu \mathrm{V})$ was significantly greater than in the control hemisphere $\left(119.6 \pm 8.0 \mu \mathrm{V}, n=12\right.$; paired $t$ test, $t_{(11)}=$ $2.23, p<0.05)$, although the difference was less than it had been $5 \mathrm{~d}$ beforehand. Therefore, LTP mimics SRP in enhancing the amplitude of the VEP and can do so over the course of at least $5 \mathrm{~d}$.

\section{LTP enhances spatial acuity and contrast sensitivity}

Having established that VEP amplitude can be increased through thalamocortical LTP, we then tested whether it would have a general effect on visual acuity and contrast sensitivity. One day after inducing saturated LTP in one hemisphere, mice were presented with a range of novel, obliquely oriented stimuli across a range of spatial frequencies and contrasts. VEPs driven across $0.05,0.15,0.3,0.45,0.6,0.8$, and $1 \mathrm{cycle}^{\circ}$ were significantly greater amplitude in the TBS hemisphere (Fig. $4 A$ ) than in the control hemisphere (two-way repeated-measures ANOVA, $F_{(1,6)}=12.21, p<0.005$ for the interaction effects of orientation and spatial frequency). The overall enhancement of visual acuity through TBS stimulation is illustrated by normalizing VEP amplitude in the TBS hemisphere to control (Fig. $4 B$ ). Even at as 
A
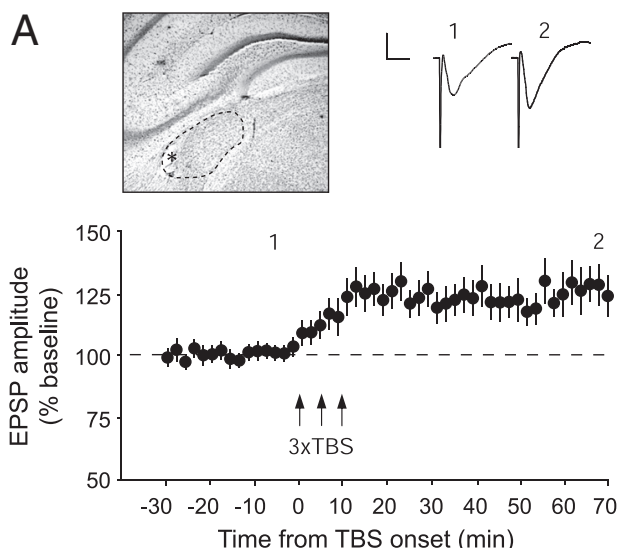

B

C
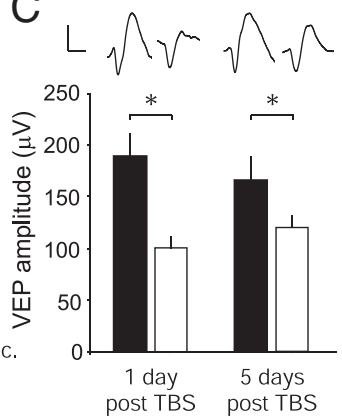

Figure 3. In vivo cortical LTP can be induced using TBS of the dLGN in isofluraneanesthetized mice. $\boldsymbol{A}$, Representative example histological section taken from an animal that underwent LTP. The concentric bipolar stimulating electrode tip (asterisk) is placed at the surface of the dLGN (demarcated by a dotted outline). Electrically evoked response amplitude is plotted as a percentage of averaged baseline in the stimulated hemisphere. Stability was determined over a $30 \mathrm{~min}$ baseline before induction of saturated LTP by delivering three epochs of TBS (arrows), each separated by $5 \mathrm{~min}$. Field potential amplitude is normalized to the average of the baseline period $(n=20)$. Each point represents an average of four samples recorded over 2 min. Examples of V1 field potentials evoked $10 \mathrm{~min}$ before LTP induction (1) and 50-60 min after the final tetanus (2) are shown at the top of the panel. Calibration: $1 \mathrm{mV}, 10 \mathrm{~ms} . \boldsymbol{B}$, Schematic illustrating the experimental setup. One hemisphere received dLGN TBS under light isoflurane general anesthesia. Field potentials were sampled through chronically implanted recording electrodes in layer 4, binocular V1 of this hemisphere. VEPs driven by a sinusoidal grating stimulus were then sampled the following day in both hemispheres (day 1) and als $05 \mathrm{~d}$ later using a novel orientation to remove any contribution of SRP. C, VEP amplitude recorded in the two hemispheres at two time points post-TBS. VEPs recorded in the TBS hemisphere (black bar) were greater amplitude $(n=13)$ than those sampled in the control hemisphere (white bar) on day 1. On day 5, VEPs recorded from the hemisphere receiving TBS were still greater amplitude $(n=13)$ than in the untetanized hemisphere. Sample VEPs are shown at the top of the panel. Calibration: $100 \mu \mathrm{V}, 50 \mathrm{~ms}$. Error bars are SEM. Asterisks represent statistical comparisons yielding significant difference $(p<0.05)$.

high a spatial frequency as $1 \mathrm{cycle} /{ }^{\circ}$, discernible VEPs emerged in the TBS hemisphere $(31.6 \pm 1.3 \mu \mathrm{V})$. These were $1.32 \pm 0.08$ times greater than evoked activity in the control hemisphere $\left(24.0 \pm 1.8 \mu \mathrm{V}\right.$; paired $t$ test, $\left.t_{(10)}=5.04, p<0.001\right)$, which was equivalent to noise $(23.9 \pm 1.2 \mu \mathrm{V})$. Contrast sensitivity was also markedly enhanced (Fig. $4 C$ ), resulting in a general increase in VEP amplitude in the tetanized hemisphere (Fig. 4D) (two-way repeated-measures ANOVA, $F_{(1,6)}=7.89, p<0.05$ for the interaction effects of orientation and contrast). TBS stimulation of the dLGN, therefore, serves as a means to enhance spatial acuity and contrast sensitivity.

\section{SRP is occluded by thalamocortical LTP}

Having shown that LTP can potentiate VEPs, we then continued to test VEP amplitude in the same group of mice $(n=13)$ over the
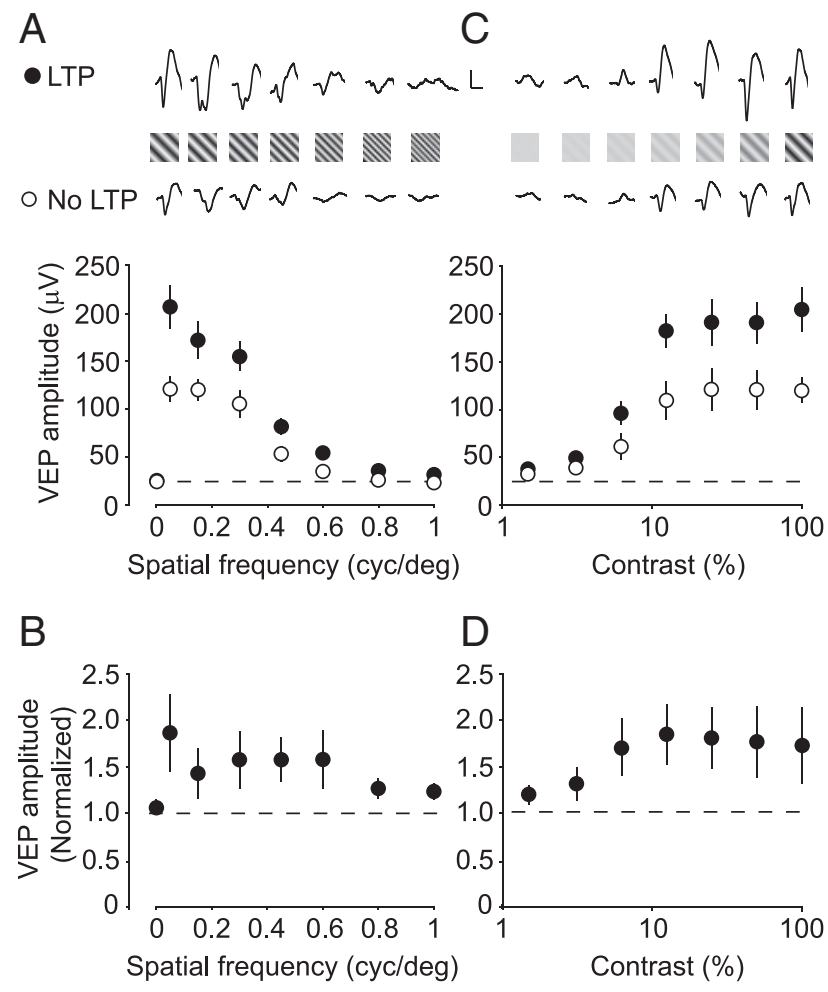

Figure 4. TBS enhances acuity and contrast sensitivity. A, LTP was induced as described previously (Fig. 3). The following day, awake, head-fixed mice were exposed to stimuli across a range of spatial frequencies $\left(0.05,0.15 .0 .3,0.45,0.6,0.8,1.0 \mathrm{cycle} /{ }^{\circ}\right)$ at a set oblique orientation. VEP amplitude was greater across all spatial frequencies in the TBS hemisphere (black circles) than the control hemisphere (white circles; $n=11$ ). Example VEP waveforms are presented from both hemispheres above the relevant graph points. Calibration: $100 \mu \mathrm{V}, 50 \mathrm{~ms}$. $\boldsymbol{B}$, TBS-induced gains in spatial acuity are revealed by normalizing VEPs in the TBS hemisphere (black circles) to the control hemisphere. C, VEP amplitude was also greater in the TBS hemisphere than the control hemisphere across a range of contrasts $(0,1.5,3.125,6.25,12.5,25,50$, and $100 \%$ ). Example waveforms are presented at the top of the panel. D, TBS-induced gains in contrast sensitivity are revealed by normalizing VEPs in the TBS hemisphere to those in the control hemisphere. Error bars in all graphs are SEM.

following $4 \mathrm{~d}$, a typical period for the emergence of asymptotic SRP (Frenkel et al., 2006) (Fig. 5A). On day 1, as reported above, VEPs recorded post-LTP were significantly greater amplitude in the TBS $(183.4 \pm 21.4 \mu \mathrm{V})$ than the control hemisphere $(100.6 \pm$ $\left.11.0 \mu \mathrm{V} ; t_{(12)}=3.16 ; p<0.01\right)$. By day 5 , however, binocular VEPs evoked in the TBS hemisphere were no longer significantly different $(253.9 \pm 29.2 \mu \mathrm{V})$ from those in the control hemisphere $\left(221.2 \pm 22.6 \mu \mathrm{V} ; t_{(12)}=1.44 ; p=0.18\right)$ (Fig. $\left.5 B, C\right)$. Thus, the ceiling level of potentiation after induction of SRP and LTP combined was equivalent to that attained through SRP alone. Normalization of day 5 VEP amplitude to day 1 (Fig. 5D) revealed that there was significantly less SRP in the tetanized hemisphere $(146.3 \pm 12.9 \%$ of day 1$)$ than the untetanized hemisphere (230.1 $\pm 10.4 \%$ of day 1 ; two-way repeated-measures ANOVA, $F_{(1,3)}=18.37 ; p<0.0005$ for the interaction effects of hemisphere treatment over days). This finding demonstrates that thalamocortical LTP significantly occludes the subsequent expression of SRP.

\section{Saturation of SRP to a single orientation occludes LTP in a stimulus-specific manner}

Having established that thalamocortical LTP could both mimic and occlude SRP, we proceeded to test whether the reverse is also true; that SRP occludes LTP. A group of P30 mice $(n=13)$ were 
A

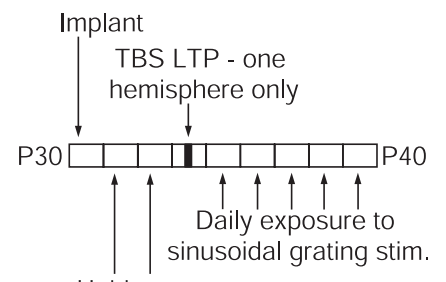

B

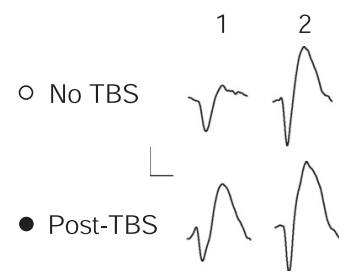

Habituate

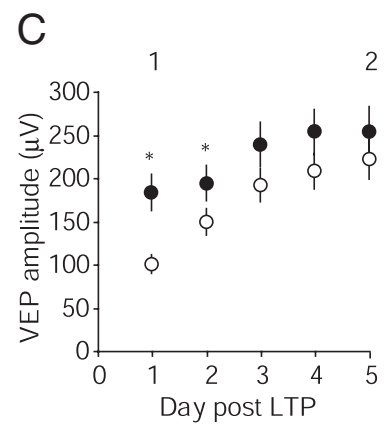

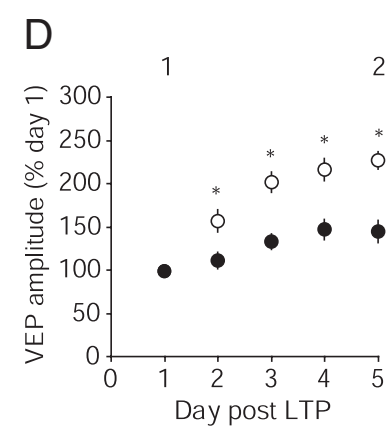

Figure 5. TBS-induced LTP in vivo occludes subsequent experience-dependent plasticity (SRP). $\boldsymbol{A}$, Experimental time course. P30 mice $(n=13)$ were implanted with VEP recording electrodes and allowed to habituate to the recording apparatus for $2 \mathrm{~d}$. LTP was induced the next day. One day later, SRP commenced and ran for 5 additional days. $\boldsymbol{B}$, Examples of VEPs recorded a day after LTP (1) and 5 l later, once SRP was saturated (2), in the TBS hemisphere (black circles) and the control hemisphere (white circles). Calibration: $100 \mu$ V, 50 ms. C, VEPs recorded in the TBS hemisphere were greater amplitude than in the control hemisphere on day 1. By day 5, VEPs driven by this same stimulus in the TBS hemisphere and the control hemisphere were of equivalent amplitude. D, VEP amplitudes normalized to day 1 values. On day 5 , VEPs were less potentiated by experience of the oriented stimulus in the TBS hemisphere than in the control hemisphere. Error bars are SEMs. Asterisks represent statistical comparisons yielding significant difference $(p<0.05)$.

implanted and habituated as described previously, before undergoing SRP to a $0.05 \mathrm{cycle}^{\circ}, 100 \%$ contrast stimulus over $5 \mathrm{~d}$. On day 5 , VEPs driven by the familiar $X^{\circ}$ stimulus and a novel $X+$ $90^{\circ}$ stimulus were recorded in both hemispheres. Afterward, mice underwent TBS stimulation of the dLGN in one hemisphere only. They were then allowed to recover overnight before again recording VEPs in awake mice, driven by either the familiar $X^{\circ}$ stimulus or a second novel $X+45^{\circ}$ stimulus, to test the contribution of TBS-induced LTP to increases in VEPs driven by either stimulus (for experimental design, see Fig. 6A, $B$ ).

Before LTP induction, VEPs driven by the familiar $X^{\circ}$ stimulus were of significantly greater amplitude $(309.2 \pm 21.0 \mu \mathrm{V} ; n=$ 13) than those driven by the novel $X+90^{\circ}$ stimulus $(183.2 \pm 18.5$ $\mu \mathrm{V}$; one-way ANOVA, $F_{(5,72)}=10.99 ; p<0.0001$; Fisher's post hoc test, $p<0.0001$ ), reflecting SRP. A day later, after LTP, VEPs driven by the same $X^{\circ}$ stimulus were no greater in amplitude $(302.6 \pm 25.3 \mu \mathrm{V})$ than they had been the day before (Fisher's post hoc test, $p=0.83$ ). However, the second novel $X+45^{\circ}$ stimulus, otherwise equivalent in all properties to both the familiar and the novel $X+90^{\circ}$ stimulus presented the day before, evoked significantly larger VEPs than the novel $X+90^{\circ}$ stimulus had the previous day $(242.8 \pm 24.5 \mu \mathrm{V}$; Fisher's post hoc test, $p<$ 0.005) (Fig. 6C). If these data are normalized to pre-TBS baseline values (Fig. $6 D$ ), the VEPs driven by the novel stimuli in the TBS hemisphere $(134.0 \pm 5.8 \%)$ show a significant potentiation after TBS (one-way ANOVA, $F_{(2,36)}=14.46 ; p<0.0001$ ) relative to the VEPs recorded from the control hemisphere $(106.9 \pm 5.4 \mu \mathrm{V}$; Fisher's post hoc test, $p<0.001$ ) and the VEPs driven by the
A

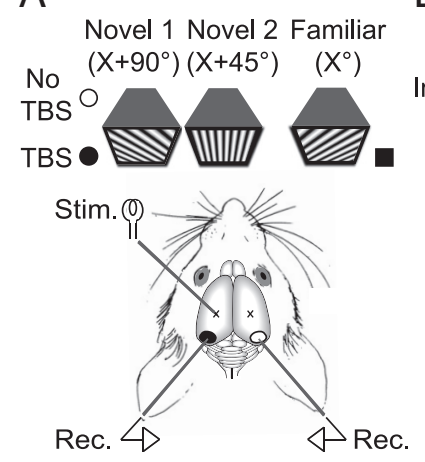

B
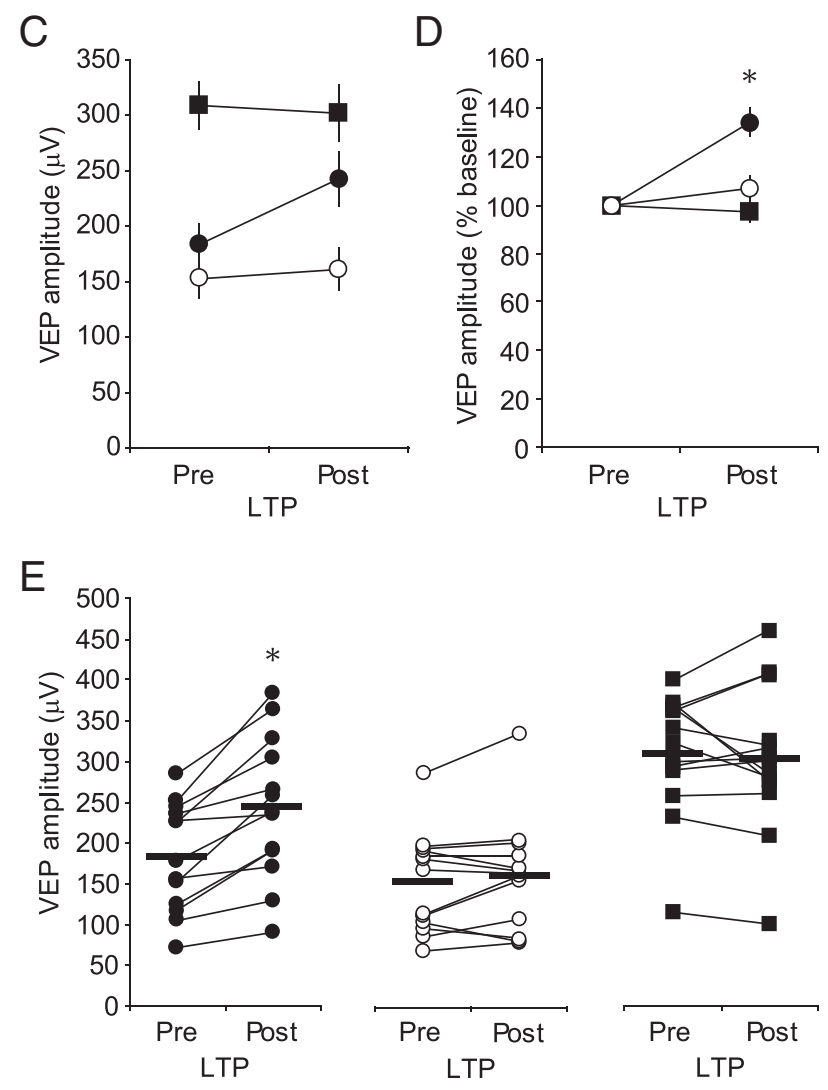

Figure 6. Thalamocortical LTP potentiates VEP amplitude selectively for novel stimuli. $A$, Experimental schematic. Awake, head-fixed mice were exposed to familiar ( $X^{\circ}$, black squares) and novel $\left(X+90^{\circ}\right.$, circles) stimuli before and after dLGN TBS in one hemisphere (black symbols). $\boldsymbol{B}$, Experimental time course. P30 mice $(n=13)$ were implanted and allowed to habituate to the recording apparatus for $2 \mathrm{~d}$. 0 day 4 , an $X^{\circ}$-oriented stimulus was presented to the animal. The same stimulus was then presented over the subsequent $4 \mathrm{~d}$. On the last day, a novel $X+90^{\circ}$ stimulus was also presented in interleaved fashion. Mice then underwent TBS-induced thalamocortical LTP. The following day, VEPs driven by $X^{\circ}$ and $X+90^{\circ}$ were recorded in both hemispheres. C, Before TBS application, VEPs driven by $X^{\circ}$ were greater amplitude in the TBS hemisphere (squares) than those driven by $X+90^{\circ}$ in either the TBS (black circles) or control hemisphere (white circles) because of SRP. In the TBS hemisphere after TBS, VEPs driven by a second novel $X+45^{\circ}$ stimulus were of close to equivalent magnitude to those driven by $X^{\circ}$, but significantly greater in amplitude than those in the control hemisphere because of LTP. $\boldsymbol{D}$, Normalization of VEPs to pre-TBS amplitude reveals that TBS induces significant potentiation of VEPs driven by novel stimuli in the TBS hemisphere but not in the control hemisphere or of VEPs evoked by the familiar $X^{\circ}$ stimulus in the TBS hemisphere. $\boldsymbol{E}$, Family of lines showing 13 individual animals included in the summary plots displayed in $\boldsymbol{C}$ and $\boldsymbol{D}$. Error bars are SEMs. Asterisks represent statistical comparisons yielding significant difference $(p<0.05)$. 
familiar $X^{\circ}$ stimulus within the TBS hemisphere $(97.3 \pm 3.7 \mu \mathrm{V}$; Fisher's post hoc test, $p<0.0001$ ). Therefore, LTP was limited to stimuli that had not previously been experienced, suggesting that SRP occludes LTP. The enhancing effect of TBS on VEPs driven by novel stimuli was limited to the TBS hemisphere as there was no similar increase in the magnitude of VEPs driven by the same novel stimuli in the control hemisphere before $(152.5 \pm 17.0 \mu \mathrm{V})$ and a day after TBS $(161.3 \pm 24.5 \mu \mathrm{V}$; Fisher's post hoc test, $p=$ 0.77 ) (Fig. 6C), demonstrating that TBS does not significantly enhance VEPs across hemispheres (Fig. 6D). The data comprising the summary plots presented in Figure 6, $C$ and $D$, are broken down into families of 13 lines for clarity (Fig. 6E). Therefore, not only does thalamocortical LTP mimic and occlude experiencedependent plasticity (SRP), but the reverse is also true: SRP occludes thalamocortical LTP.

\section{SRP maintenance is reversed by local inhibition of PKM $\zeta$}

Maintenance of NMDA receptor-dependent LTP depends on $\mathrm{PKM} \zeta$, an atypical, constitutively active isoform of the calciumdependent kinase PKC (Pastalkova et al., 2006). Given the dependence of SRP on NMDA receptor activation (Frenkel et al., 2006) and the involvement of expression mechanisms shared with many forms of LTP, we tested whether local infusions of ZIP into the binocular zone of mouse primary visual cortex would erase SRP. Mice (P30) were implanted as described previously with the addition of bilateral infusion cannulae positioned proximal to the recording site $(n=9)$ (Fig. $7 A)$. After $2 \mathrm{~d}$ of recovery and habituation, an $X^{\circ}$ stimulus was presented repeatedly over $5 \mathrm{~d}$, resulting in saturated SRP $(248.5 \pm 27.9 \%$ of averaged day 1 value). On day 5 , a novel $X+90^{\circ}$ stimulus was also presented, which elicited significantly smaller VEPs $\left(135.8 \pm 12.5 \%\right.$; $t_{(8)}=$ 3.89 ; $p<0.005)$ demonstrating the stimulus selectivity of SRP (Fig. $7 C, D$ ).

$X+90^{\circ}$ was then presented over 4 additional days, resulting in SRP equivalent to that observed in phase one $(287.9 \pm 24.9 \%$; two-way repeated-measures ANOVA, $F_{(1,4)}=0.168 ; p=0.95$ for the interaction effects of orientation over days). On day 9 , a third $X+45^{\circ}$ stimulus was presented, interleaved with the $X+90^{\circ}$ stimulus. As on day 5 , VEPs evoked by the familiar stimulus $(287.9 \pm 24.9 \%)$ were greater amplitude than for the novel stimulus $\left(147.3 \pm 12.5 \% ; t_{(8)}=7.781 ; p<0.0001\right)$. After the sequential establishment of SRP to two different stimuli, $1 \mu$ l of ZIP (10 $\mathrm{nmol} / \mu \mathrm{l}$ ) was infused using a microinfusion pump over $10 \mathrm{~min}$ while the animal remained in the recording apparatus. One hour later, VEPs evoked by the novel $X+45^{\circ}$ stimulus (140.9 $\left.\pm 7.0 \%\right)$ were not significantly different in amplitude from those recorded $1 \mathrm{~h}$ earlier $\left(147.3 \pm 12.5 \% ; t_{(8)}=0.94 ; p=0.93\right)$, indicating no effect of the infusion or inhibitor on baseline VEPs. In contrast, VEPs evoked by the familiar $X+90^{\circ}$ stimulus had dropped significantly in amplitude ( $150.2 \pm 7.9 \%$ day 1 values, $t_{(8)}=5.31$; $p<0.001)$ and were now not significantly different from those evoked by the novel stimulus $\left(t_{(8)}=1.10 ; p=0.31\right)$, indicating that ZIP had erased recently saturated SRP (Fig. $7 C, D$ ).

\section{SRP can be reinstated after ZIP infusion but does not spontaneously recover}

If SRP can be entirely erased without long-lasting insult to visual cortex, then it should be possible to reinduce SRP to the same stimulus. To test this possibility, both the previously familiar $X+$ $90^{\circ}$ and novel $X+45^{\circ}$ stimuli were presented, interleaved, over the next $4 \mathrm{~d}$. Four days after ZIP application, on overall day 13 of the experiment, VEPs evoked by $X+90^{\circ}(232.6 \pm 14.8 \%)$ were significantly greater in amplitude than when first recorded after

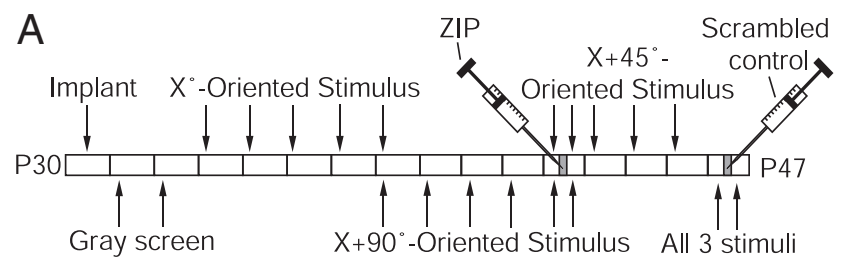

$B$
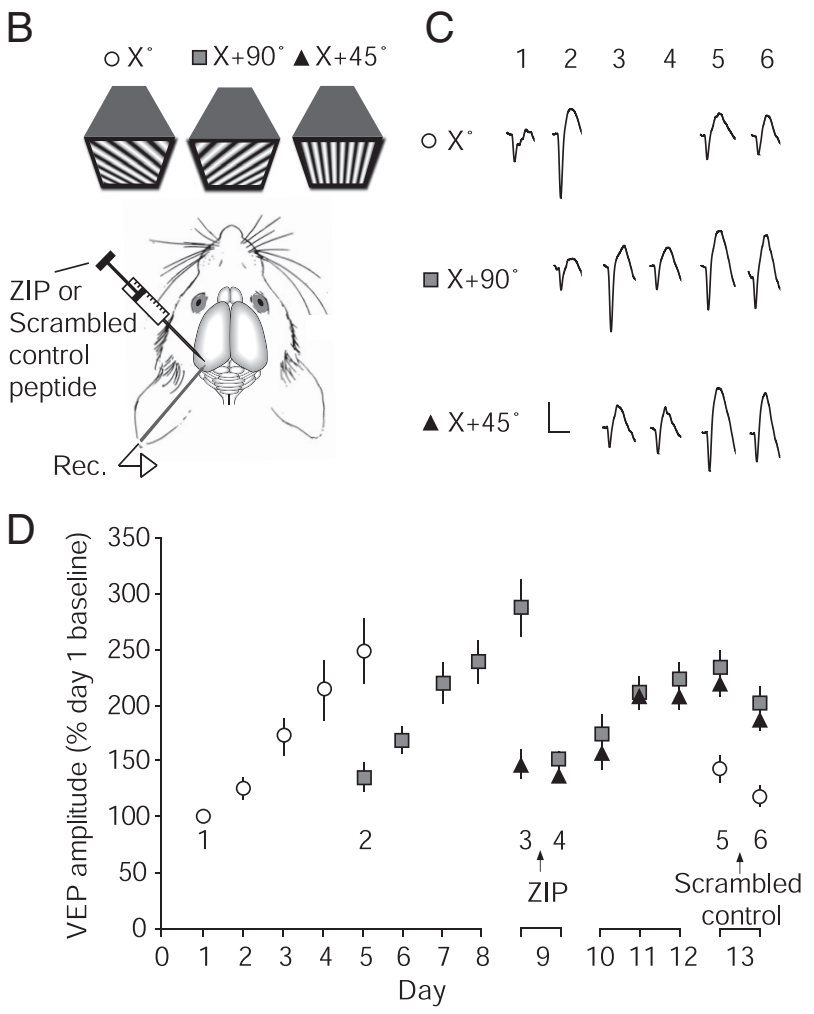

Figure 7. PKM $\zeta$ is necessary for SRP maintenance. $A$, Experimental time course. P30 mice $(n=9)$ were implanted both with recording electrodes and guide cannulae. On recovery, they were habituated to the recording apparatus over $2 \mathrm{~d}$. Mice were then presented with an $X^{\circ}$ stimulus across the following $5 \mathrm{~d}$. This stimulus was not then presented again until the final day of the experiment. On day 5 of $X^{\circ}$ presentation, a novel $X+90^{\circ}$ stimulus was also presented and continued to be presented for the remainder. On day 5 of $X+90^{\circ}$ stimulus presentation, a second novel $X+45^{\circ}$ stimulus was also presented in interleaved fashion. Immediately after $X+90^{\circ}$ and $X+45^{\circ}$ presentation, a $1 \mu$ linjection of the PKM $\zeta$-specific inhibitory peptide, ZIP, was administered to the recording area over $10 \mathrm{~min}$. One hour later, VEPs driven by $X+90^{\circ}$ and $X+45^{\circ}$ stimuli were again sampled. These two stimuli were then presented repeatedly over the following $4 \mathrm{~d}$. On the final day of the experiment, all three stimuli were presented in interleaved fashion. Immediately afterward, a $1 \mu$ i injection of scrambled, control peptide was administered to the recording area over $10 \mathrm{~min}$. One hour later, VEPs driven by all three stimuli were again recorded. $\boldsymbol{B}$, Experimental schematic. Head-fixed, awake animals with chronically implanted recording electrodes and guide cannulae in binocular V1 were presented with $X^{\circ}$ (white circles), $X+90^{\circ}$ (gray squares), and $X+45^{\circ}$ (black triangles) stimuli and received ZIP or scrambled peptide infusions at various time points over the course of the experiment. C, Example VEP waveforms driven by three orientations at pertinent time points during SRP, SRP erasure by ZIP, SRP reinstatement and after infusion of a control scrambled peptide. Calibration: $100 \mu \mathrm{V}, 50 \mathrm{~ms}$. D, VEPs driven by $X^{\circ}$ (white circles) underwent SRP over the first $5 \mathrm{~d}$ of the experiment. On day $5, X+90^{\circ}$ evoked significantly lower amplitude VEPs (gray squares), demonstrating stimulus specificity. By day 9 , VEPs evoked by $X+90^{\circ}$ had undergone significant SRP, whereas the second novel $X+45^{\circ}$ stimulus (black triangles) evoked unpotentiated VEPs. ZIP was then infused proximal to the recording site. One hour later, VEPs driven by $X+90^{\circ}$ and $X+45^{\circ}$ were of comparable unpotentiated amplitude, demonstrating erasure of SRP by ZIP. Repeated re-presentation of both stimuli then induced equivalent SRP over the following days. On day 13, 1 week after the most recent presentation, $X^{\circ}$ evoked significantly lower amplitude VEPs than either of the other orientations or the $X^{\circ}$ stimulus on day 5 before ZIP. Finally, on day 13 , a control peptide was infused proximal to the recording site. One hour after infusion of this peptide, VEPs driven by the $X^{\circ}, X+90^{\circ}$, and $X+45^{\circ}$ stimulus maintained comparable values to before the infusion. Error bars are SEMs. 
ZIP application $\left(150.2 \pm 7.9 \% ; t_{(8)}=4.38 ; p<0.005\right)$. Therefore, we conclude that SRP could be reinduced after saturated SRP had previously been erased by ZIP. Moreover, the degree and rate of SRP reacquisition was equivalent to the original acquisition (twoway repeated-measures ANOVA, $F_{(1,4)}=1.36$; $p=0.26$ for interaction effect between ZIP treatment and day), suggesting that there were no savings after ZIP-mediated erasure of SRP (Fig. $7 C, D)$. VEPs evoked by the novel $X+45^{\circ}$ stimulus on day 13 $(218.9 \pm 10.5 \%)$ had undergone an equivalent degree and rate of SRP to the other two stimuli (two-way repeated-measures ANOVA, $F_{(4,16)}=1.75 ; p=0.06$ for interaction effect between orientation and day) demonstrating that the application of ZIP does not impact subsequent SRP.

VEPs driven by the original $X^{\circ}$ stimulus, which the animals had not seen over the previous week, were also interleaved among these recordings on day 13. These VEPs (142.8 \pm $12.0 \%)$ were significantly lower amplitude than they had been on day $5\left(248.5 \pm 27.9 \% ; t_{(8)}=4.51 ; p<0.005\right)$. They were also significantly lower amplitude than those evoked by $X+$ $90^{\circ}(232.6 \pm 14.8 \%)$ and $X+45^{\circ}$ stimuli on the same day $\left(218.9 \pm 10.5 \% ; F_{(2,27)}=19.36 ; p<0.001\right.$; Fisher's post hoc test, $p<0.001$ for comparisons between $X^{\circ}$ and either other orientation; $p>0.05$ for comparison between $X+90^{\circ}$ and $X$ $+45^{\circ}$ ) after SRP, but equivalent in amplitude to those evoked by $X+90^{\circ}(150.2 \pm 7.9 \%)$ and $X+45^{\circ}$ before SRP $(147.3 \pm$ $12.5 \%$, respectively; $\left.F_{(2,27)}=0.98 ; p>0.05\right)$. Under normal circumstances, SRP is known to be maintained for at least a week without a requirement for additional presentation of visual stimuli (Frenkel et al., 2006). Thus, SRP to the original $X^{\circ}$ stimulus had been erased on day 9 by ZIP application and showed no signs of spontaneous recovery in the intervening week (Fig. 7C,D).

A final test of the specificity of ZIP action was provided at this stage by infusing $1 \mu \mathrm{l}$ of a control peptide $(10 \mathrm{nmol} / \mu \mathrm{l})$ with the same constituent amino acids as ZIP but in scrambled order, as used in previous studies of ZIP action (Pastalkova et al., 2006; Shema et al., 2007). One hour after infusion of this peptide, VEPs evoked by the $X^{\circ}$ stimulus $(118.7 \pm 9.1 \%)$ were still significantly smaller than those evoked by the $X+90^{\circ}(201.2 \pm 14.8 \%)$ or $X+$ $45^{\circ}$ stimulus $\left(186.8 \pm 9.5 \% ; F_{(2,27)}=17.10 ; p<0.001\right.$; Fisher's post hoc test, $p<0.001$ for comparisons between $X^{\circ}$ and either other orientation; $p>0.05$ for comparison between $X+90^{\circ}$ and $\left.X+45^{\circ}\right)$. Therefore, the actions of ZIP in erasing SRP are not a general result of infusion but specific to the inhibition of PKM $\zeta$. These data demonstrate a critical role for $\mathrm{PKM} \zeta$ in maintaining SRP (Fig. 7C,D).

\section{Discussion}

We show that TBS of the dLGN can induce LTP of VEPs driven by a wide range of stimuli, including those with high spatial frequencies and low contrasts. This LTP occludes SRP, an experience-dependent form of plasticity and a surrogate measure of perceptual learning. Conversely, SRP prevents TBS from further potentiating the VEPs evoked by the experienced, but not novel, stimuli in vivo. This mutual occlusion suggests that LTP and SRP share core expression mechanisms. Consistent with this conclusion, we find that local inhibition of PKM $\zeta$, a constitutively active kinase known to maintain NMDA receptordependent LTP and memory (Serrano et al., 2005; Pastalkova et al., 2006), reverses SRP in the visual cortex.

\section{TBS of the dLGN induces LTP at mature visual cortical synapses}

In the slice preparation, it has been reported that somatosensory thalamocortical LTP cannot be induced past postnatal day 9 in rats (Crair and Malenka, 1995; Barth and Malenka, 2001). This window may close later in the visual system (Kirkwood et al., 1995; Wang and Daw, 2003), but it is nevertheless reported to be difficult to induce LTP at thalamocortical synapses in slices taken from animals around P30 or later. These findings contrast with the observations that substantial LTP can be induced in the visual (Heynen and Bear, 2001; Dringenberg et al., 2004; Kuo and Dringenberg, 2009), auditory (Hogsden and Dringenberg, 2009), and somatosensory cortices (Lee and Ebner, 1992) by stimulation of the thalamus or white matter in intact adult rodents. One possible explanation for this discrepancy has been that the inhibitory tone of the cortex is altered in ex vivo preparations. Indeed, in the cortical slice, LTP that is not normally present can emerge in the presence of a $\mathrm{GABA}_{\mathrm{A}}$ receptor antagonist (Artola and Singer, 1987; Kirkwood and Bear, 1994; Wang and Daw, 2003) (but see Jiang et al., 2007). Metaplasticity of the LTP threshold offers another potential explanation as we allow the mice $2 \mathrm{~h}$ of dark exposure before the application of an electrical tetanus to dLGN. Sensory deprivation before the delivery of thalamocortical tetanic stimulation has been shown to facilitate LTP induction (Kuo and Dringenberg, 2009).

Enhancement of thalamocortical transmission by highfrequency electrical stimulation can also reflect changes in the excitability of the thalamus, rather than synaptic LTP in the cortex (Hirata and Castro-Alamancos, 2006). However, the mutual occlusion of SRP and LTP indicate that, in substantial part, the potentiation of VEPs by TBS results from changes in the strength of cortical synapses rather than altered thalamic excitability, since SRP is disrupted by manipulations local to the visual cortex (Frenkel et al., 2006), including injection of the ZIP peptide.

Although the data indicate that cortical synapses are potentiated by thalamic TBS, it remains to be determined which synapses are involved. The VEP is a local field potential composed of events within a small population of synapses surrounding the recording electrode (Katzner et al., 2009). When the recording electrode is positioned in layer 4 of the cortex, a substantial component of the VEP represents direct thalamocortical synaptic events (Liu et al., 2007; Yoon et al., 2009; Khibnik et al., 2010). However, later components of the field potential likely reflect intracortical synaptic events. We cannot discount the possibility that LTP induced by dLGN stimulation may result from strengthening of intracortical synapses. Future studies will determine how plasticity at different populations of synapses within visual cortex contribute to the observed LTP of VEPs.

\section{LTP mechanisms are sufficient to account for SRP}

Several previous studies have demonstrated learning-related potentiation of synaptic strength in the hippocampus (Doyère et al., 1995; Sacchetti et al., 2002; Gruart et al., 2006; Whitlock et al., 2006) and the amygdala (Rogan et al., 1997; Rumpel et al., 2005; Schafe et al., 2005; Tye et al., 2008). Most pertinent to the study described here, learning can also induce LTP-like changes in synaptic strength in the neocortex (Rioult-Pedotti et al., 1998, 2000). In these latter studies, learning occluded ex vivo cortical LTP. However, mutual occlusion, whereby LTP also prevents subsequent learning, was not demonstrated. This leaves open the possibility that experience induces an alteration of LTP threshold through metaplasticity (Abraham, 2008). Previous studies in the hippocampus have demonstrated that LTP can disrupt subse- 
quent learning (Barnes et al., 1994; Moser et al., 1998; Madroñal et al., 2007) (but see Jeffery and Morris, 1993). However, the experiments presented here are the first to show that occlusion effects are limited to previously activated synapses without preventing additional change at neighboring synapses. SRP in the mouse visual system provides a perfect opportunity to address this issue of specificity because the potentiating effect is limited to a clearly defined stimulus. If inputs onto the same population of postsynaptic cells are altered during SRP, as is suggested by the eye specificity of the phenomenon, then cell-wide metaplastic changes cannot account for the stimulus-specific occlusion of LTP by SRP. We therefore conclude that SRP uses the same core mechanisms to potentiate synapses in the visual cortex as support potentiation by thalamocortical LTP.

We find that SRP is disrupted by the ZIP peptide that inhibits PKM $\zeta$. ZIP erases LTP in the hippocampus (Serrano et al., 2005; Pastalkova et al., 2006) and memory of various forms in the hippocampus (Pastalkova et al., 2006; Serrano et al., 2008; Hardt et al., 2010), amygdala (Serrano et al., 2008), and neocortex (Shema et al., 2007, 2009). The effect of ZIP on SRP appears specific to the inhibition of PKM $\zeta$ because a scrambled control does not significantly affect already established SRP. Crucially, we demonstrate that SRP can reemerge to a familiar stimulus at the same rate as it emerges for the first time to a novel stimulus. Moreover, we demonstrate that no spontaneous recovery of synaptic potentiation occurs after initial erasure by ZIP and that SRP stays reversed for at least 1 week. These findings are consistent with SRP being maintained in the visual cortex using mechanisms similar to LTP in CA1 (Ling et al., 2002; Serrano et al., 2005) and the dentate gyrus (Pastalkova et al., 2006). We know from previous work that $\mathrm{SRP}$ is dependent on the NMDA receptor for induction, and the insertion of GluR1 AMPA receptor subunits for expression (Frenkel et al., 2006). These are mechanisms shared with the canonical form of CA1 LTP and we now extend the list of commonalities by demonstrating the involvement of $\mathrm{PKM} \zeta$ in the maintenance of SRP.

Given the mutual occlusion that exists between the two phenomena, it is fair to describe SRP as a biomarker of LTP. SRP therefore could serve as a naturalistic means of assessing synaptic plasticity. Relatively unchallenging electrophysiological methods are required to record and analyze SRP and it is an extremely reliable phenomenon. It seems likely that SRP is a general phenomenon in sensory cortex because similar effects have been observed in other animal species (Clapp et al., 2006; Hua et al., 2010), including humans (Clapp et al., 2005b; McNair et al., 2006; Ross et al., 2008). Thus, SRP provides a means to interrogate the integrity of neocortical LTP mechanisms, and could be used, for example, to assess the effectiveness of experimental therapeutic interventions in animals and humans.

\section{Sensory gains through SRP and LTP}

It has been suggested that SRP reveals a core mechanism for perceptual learning in the visual system (Frenkel et al., 2006). Perceptual learning is of great interest not just in the context of basic research but also from a clinical perspective. Amblyopia is a disorder resulting from deprivation of vision early in life that afflicts as many as 1-2\% of people in the world (Webber and Wood, 2005). Disruption of cortical development through deprivation cannot be rescued after $\sim 8$ years of age in humans even if visual function is entirely recovered, because plasticity mechanisms are altered in adulthood. Perceptual learning can occur in adults and has been used to recover visual function in amblyopics (Li et al., 2007; Chen et al., 2008; Polat et al., 2009).
One issue with the use of perceptual learning to recover visual function is that it is so specific to individual stimuli that a complex and lengthy training schedule would be required to significantly recover visual function. Our results here demonstrate that dLGN TBS-induced LTP can dramatically enhance both visual acuity and contrast sensitivity, at least at the level of the VEP, across a wide range of stimulus orientations. Recent work has suggested that it is possible to noninvasively induce LTP in primary sensory cortices of rats (Uhlrich et al., 2005; Manning et al., 2007) and humans (Clapp et al., 2005a,b) using photic or auditory tetani. Another alternative may be the use of transcranial magnetic stimulation, either on its own or in conjunction with visual stimulation, to noninvasively deliver a potentiating tetanus (for review, see Cooke and Bliss, 2006). Our results suggest that, should we identify a successful noninvasive technique in the future, a broader-based LTP of synaptic transmission in the visual cortex may be sufficient to recover visual function in an immediate and general fashion in amblyopics.

\section{References}

Abraham WC (2008) Metaplasticity: tuning synapses and networks for plasticity. Nat Rev Neurosci 9:387.

Artola A, Singer W (1987) Long-term potentiation and NMDA receptors in rat visual cortex. Nature 330:649-652.

Barnes CA, Jung MW, McNaughton BL, Korol DL, Andreasson K, Worley PF (1994) LTP saturation and spatial learning disruption: effects of task variables and saturation levels. J Neurosci 14:5793-5806.

Barth AL, Malenka RC (2001) NMDAR EPSC kinetics do not regulate the critical period for LTP at thalamocortical synapses. Nat Neurosci 4:235-236.

Bliss TV, Lømo T (1973) Long-lasting potentiation of synaptic transmission in the dentate area of the anaesthetized rabbit following stimulation of the perforant path. J Physiol 232:331-356.

Chen PL, Chen JT, Fu JJ, Chien KH, Lu DW (2008) A pilot study of anisometropic amblyopia improved in adults and children by perceptual learning: an alternative treatment to patching. Ophthalmic Physiol Opt 28:422-428.

Clapp WC, Kirk IJ, Hamm JP, Shepherd D, Teyler TJ (2005a) Induction of LTP in the human auditory cortex by sensory stimulation. Eur J Neurosci 22:1135-1140.

Clapp WC, Zaehle T, Lutz K, Marcar VL, Kirk IJ, Hamm JP, Teyler TJ, Corballis MC, Jancke L (2005b) Effects of long-term potentiation in the human visual cortex: a functional magnetic resonance imaging study. Neuroreport 16:1977-1980.

Clapp WC, Eckert MJ, Teyler TJ, Abraham WC (2006) Rapid visual stimulation induces $N$-methyl-D-aspartate receptor-dependent sensory longterm potentiation in the rat cortex. Neuroreport 17:511-515.

Cooke SF, Bliss TV (2006) Plasticity in the human central nervous system. Brain 129:1659-1673.

Crair MC, Malenka RC (1995) A critical period for long-term potentiation at thalamocortical synapses. Nature 375:325-328.

Doyère V, Rédini-Del Negro C, Dutrieux G, Le Floch G, Davis S, Laroche S (1995) Potentiation or depression of synaptic efficacy in the dentate gyrus is determined by the relationship between the conditioned and unconditioned stimulus in a classical conditioning paradigm in rats. Behav Brain Res 70:15-29.

Dringenberg HC, Kuo MC, Tomaszek S (2004) Stabilization of thalamocortical long-term potentiation by the amygdala: cholinergic and transcription-dependent mechanisms. Eur J Neurosci 20:557-565.

Fahle M, Morgan M (1996) No transfer of perceptual learning between similar stimuli in the same retinal position. Curr Biol 6:292-297.

Frenkel MY, Bear MF (2004) How monocular deprivation shifts ocular dominance in visual cortex of young mice. Neuron 44:917-923.

Frenkel MY, Sawtell NB, Diogo AC, Yoon B, Neve RL, Bear MF (2006) Instructive effect of visual experience in mouse visual cortex. Neuron 51:339-349.

Furmanski CS, Schluppeck D, Engel SA (2004) Learning strengthens the response of primary visual cortex to simple patterns. Curr Biol 14:573-578. 
Gilbert CD, Sigman M, Crist RE (2001) The neural basis of perceptual learning. Neuron 31:681-697.

Gruart A, Muñoz MD, Delgado-García JM (2006) Involvement of the CA3CA1 synapse in the acquisition of associative learning in behaving mice. J Neurosci 26:1077-1087.

Hardt O, Migues PV, Hastings M, Wong J, Nader K (2010) PKMzeta maintains 1-day- and 6-day-old long-term object location but not object identity memory in dorsal hippocampus. Hippocampus 20:691-695.

Heynen AJ, Bear MF (2001) Long-term potentiation of thalamocortical transmission in the adult visual cortex in vivo. J Neurosci 21:9801-9813.

Hirata A, Castro-Alamancos MA (2006) Relief of synaptic depression produces long-term enhancement in thalamocortical networks. J Neurophysiol 95:2479-2491.

Hogsden JL, Dringenberg HC (2009) Decline of long-term potentiation (LTP) in the rat auditory cortex in vivo during postnatal life: involvement of NR2B subunits. Brain Res 1283:25-33.

Hua T, Bao P, Huang CB, Wang Z, Xu J, Zhou Y, Lu ZL (2010) Perceptual learning improves contrast sensitivity of V1 neurons in cats. Curr Biol 20:887-894.

Jeffery KJ, Morris RG (1993) Cumulative long-term potentiation in the rat dentate gyrus correlates with, but does not modify, performance in the water maze. Hippocampus 3:133-140.

Jiang B, Treviño M, Kirkwood A (2007) Sequential development of longterm potentiation and depression in different layers of the mouse visual cortex. J Neurosci 27:9648-9652.

Karni A, Bertini G (1997) Learning perceptual skills: behavioral probes into adult cortical plasticity. Curr Opin Neurobiol 7:530-535.

Katzner S, Nauhaus I, Benucci A, Bonin V, Ringach DL, Carandini M (2009) Local origin of field potentials in visual cortex. Neuron 61:35-41.

Khibnik LA, Cho KK, Bear MF (2010) Relative contribution of feedforward excitatory connections to expression of ocular dominance plasticity in layer 4 of visual cortex. Neuron 66:493-500.

Kirkwood A, Bear MF (1994) Hebbian synapses in visual cortex. J Neurosci 14:1634-1645.

Kirkwood A, Lee HK, Bear MF (1995) Co-regulation of long-term potentiation and experience-dependent plasticity in visual cortex by age and experience. Nature 375:328-331.

Kuo MC, Dringenberg HC (2009) Short-term (2 to $5 \mathrm{~h}$ ) dark exposure lowers long-term potentiation (LTP) induction threshold in rat primary visual cortex. Brain Res 1276:58-66.

Lee SM, Ebner FF (1992) Induction of high frequency activity in the somatosensory thalamus of rats in vivo results in long-term potentiation of responses in SI cortex. Exp Brain Res 90:253-261.

Li RW, Provost A, Levi DM (2007) Extended perceptual learning results in substantial recovery of positional acuity and visual acuity in juvenile amblyopia. Invest Ophthalmol Vis Sci 48:5046-5051.

Ling DS, Benardo LS, Serrano PA, Blace N, Kelly MT, Crary JF, Sacktor TC (2002) Protein kinase Mzeta is necessary and sufficient for LTP maintenance. Nat Neurosci 5:295-296.

Liu BH, Wu GK, Arbuckle R, Tao HW, Zhang LI (2007) Defining cortical frequency tuning with recurrent excitatory circuitry. Nat Neurosci 10:1594-1600.

Madroñal N, Delgado-García JM, Gruart A (2007) Differential effects of long-term potentiation evoked at the CA3 CA1 synapse before, during, and after the acquisition of classical eyeblink conditioning in behaving mice. J Neurosci 27:12139-12146.

Malenka RC, Bear MF (2004) LTP and LTD: an embarrassment of riches. Neuron 44:5-21.

Manning KA, Galganski LA, Uhlrich DJ (2007) Photic-induced sensitization: eye-specific neural plasticity and effect of behavioral state. Neuroscience 146:1413-1424.

Martin SJ, Grimwood PD, Morris RG (2000) Synaptic plasticity and memory: an evaluation of the hypothesis. Annu Rev Neurosci 23:649-711.

McNair NA, Clapp WC, Hamm JP, Teyler TJ, Corballis MC, Kirk IJ (2006) Spatial frequency-specific potentiation of human visual-evoked potentials. Neuroreport 17:739-741.
Moser EI, Krobert KA, Moser MB, Morris RG (1998) Impaired spatial learning after saturation of long-term potentiation. Science 281:2038-2042.

Neves G, Cooke SF, Bliss TV (2008) Synaptic plasticity, memory and the hippocampus: a neural network approach to causality. Nat Rev Neurosci 9:65-75.

Pastalkova E, Serrano P, Pinkhasova D, Wallace E, Fenton AA, Sacktor TC (2006) Storage of spatial information by the maintenance mechanism of LTP. Science 313:1141-1144.

Poggio T, Fahle M, Edelman S (1992) Fast perceptual learning in visual hyperacuity. Science 256:1018-1021.

Polat U, Ma-Naim T, Spierer A (2009) Treatment of children with amblyopia by perceptual learning. Vision Res 49:2599-2603.

Rioult-Pedotti MS, Friedman D, Hess G, Donoghue JP (1998) Strengthening of horizontal cortical connections following skill learning. Nat Neurosci 1:230-234.

Rioult-Pedotti MS, Friedman D, Donoghue JP (2000) Learning-induced LTP in neocortex. Science 290:533-536.

Rogan MT, Stäubli UV, LeDoux JE (1997) Fear conditioning induces associative long-term potentiation in the amygdala. Nature 390:604-607.

Ross RM, McNair NA, Fairhall SL, Clapp WC, Hamm JP, Teyler TJ, Kirk IJ (2008) Induction of orientation-specific LTP-like changes in human visual evoked potentials by rapid sensory stimulation. Brain Res Bull 76: 97-101.

Rumpel S, LeDoux J, Zador A, Malinow R (2005) Postsynaptic receptor trafficking underlying a form of associative learning. Science 308:83-88.

Sacchetti B, Lorenzini CA, Baldi E, Bucherelli C, Roberto M, Tassoni G, Brunelli M (2002) Time-dependent inhibition of hippocampal LTP in vitro following contextual fear conditioning in the rat. Eur J Neurosci 15:143-150.

Sawtell NB, Frenkel MY, Philpot BD, Nakazawa K, Tonegawa S, Bear MF (2003) NMDA receptor-dependent ocular dominance plasticity in adult visual cortex. Neuron 38:977-985.

Schafe GE, Doyère V, LeDoux JE (2005) Tracking the fear engram: the lateral amygdala is an essential locus of fear memory storage. J Neurosci 25:10010-10014.

Serrano P, Yao Y, Sacktor TC (2005) Persistent phosphorylation by protein kinase $\mathrm{M} \zeta$ maintains late-phase long-term potentiation. J Neurosci 25:1979-1984.

Serrano P, Friedman EL, Kenney J, Taubenfeld SM, Zimmerman JM, Hanna J, Alberini C, Kelley AE, Maren S, Rudy JW, Yin JC, Sacktor TC, Fenton AA (2008) PKMzeta maintains spatial, instrumental, and classically conditioned long-term memories. PLoS Biol 6:2698-2706.

Shema R, Sacktor TC, Dudai Y (2007) Rapid erasure of long-term memory associations in the cortex by an inhibitor of PKM zeta. Science 317: 951-953.

Shema R, Hazvi S, Sacktor TC, Dudai Y (2009) Boundary conditions for the maintenance of memory by PKMzeta in neocortex. Learn Mem 16:122-128.

Tye KM, Stuber GD, de Ridder B, Bonci A, Janak PH (2008) Rapid strengthening of thalamo-amygdala synapses mediates cue-reward learning. Nature 453:1253-1257.

Uhlrich DJ, Manning KA, O'Laughlin ML, Lytton WW (2005) Photicinduced sensitization: acquisition of an augmenting spike-wave response in the adult rat through repeated strobe exposure. J Neurophysiol 94:3925-3937.

Wang XF, Daw NW (2003) Long term potentiation varies with layer in rat visual cortex. Brain Res 989:26-34.

Webber AL, Wood J (2005) Amblyopia: prevalence, natural history, functional effects and treatment. Clin Exp Optom 88:365-375.

Whitlock JR, Heynen AJ, Shuler MG, Bear MF (2006) Learning induces long-term potentiation in the hippocampus. Science 313:1093-1097.

Yoon BJ, Smith GB, Heynen AJ, Neve RL, Bear MF (2009) Essential role for a long-term depression mechanism in ocular dominance plasticity. Proc Natl Acad Sci U S A 106:9860-9865. 